\title{
Myxedema Coma in a Hypothermic, Obtunded Patient with Post-renal Acute Kidney Injury and Bacteremia in the Intensive Care Unit
}

Hernan Franco Lopez, MD; Sameer Sharif, MD; John Centofanti, MD

\section{About the Authors:}

Hernan Franco Lopez is PGY2 Internal Medicine Resident, Department of Medicine Internal Medicine Program - Department of Medicine at McMaster University

Sameer Sharif is PGY 5 Emergency Medicine, a Fellow - Critical Care Medicine, and an Education Scholar with the Clinician Educator Program, Division of Emergency Medicine - Department of Medicine at McMaster University John Centofanti is an Anesthesiologist - Department of Anesthesia, an Intensivist - Division of Critical Care, and an Assistant Professor at McMaster University

Submitted: July 29, 2018. Accepted: August 31, 2018. Published: May 21, 2019. DOI: 10.22374/cjgim.v14i2.304

\begin{abstract}
We present a case of a hypothermic, unconscious patient transferred to our Intensive Care Unit with sepsis requiring mechanical ventilation. The absence of any known past medical history as well as concurrent obstructive uropathy and bacteremia made initial diagnosis challenging. He was eventually found to be in myxedema coma in light of evolving signs and laboratory investigations. This case emphasizes the need to consider myxedema coma in the differential diagnosis of profound hypothermia, especially when other clinical signs and symptoms may obscure its initial diagnosis, and lead clinicians to focus on the triggering event in isolation rather than concurrently managing hypothyroidism. This case highlights a challenging presentation of an uncommon, but life-threatening condition. We discuss the signs and symptoms present in the hypothyroid patient with myxedema coma; emphasize the pathophysiology of myxedema coma as well as the evidence-based acute management of this condition.
\end{abstract}

\section{Résumé}

Nous présentons le cas d'un patient hypothermie, inconscient, transféré à notre unité de soins intensifs avec septicémie nécessitant une ventilation mécanique. L'absence d’antécédents médicaux connus ainsi que d'uropathie obstructive et de bactériémie concomitantes ont rendu le diagnostic initial difficile. On a finalement découvert qu'il était dans le coma du myxœè̀me à la lumière de lévolution des signes et des examens de laboratoire. Ce cas met l'accent sur la nécessité de tenir compte du coma myxœdème dans le diagnostic différentiel de l'hypothermie profonde, surtout lorsque d'autres signes et symptômes cliniques peuvent masquer le diagnostic initial, et inciter les cliniciens à se concentrer sur lévénement déclencheur de façon isolée plutôt que de gérer simultanément l'hypothyroïdie. Ce cas met en évidence la présentation difficile d'une maladie rare, mais potentiellement mortelle. Nous discutons des signes et symptômes présents chez le patient hypothyroïdien atteint d'un coma myxœdème ; nous mettons l'accent sur la pathophysiologie du coma myxœème ainsi que sur la prise en charge aiguë de cette affection fondée sur des données probantes. 


\section{Case}

A 64-year-old man with unknown medical history was brought to a peripheral hospital after being found unconscious at home. He was last seen a day earlier by a friend who reported that he was complaining of shortness of breath, but no other symptoms. On arrival he had a Glasgow Coma Scale score of 4 and was intubated for airway protection. Vital signs showed a temperature of $32^{\circ} \mathrm{C}$, a heart rate of 84 beats per minute $(\mathrm{bpm})$ and a normal blood pressure $(136 / 58 \mathrm{mmHg})$. Initial laboratory test results revealed a severe metabolic acidosis $(\mathrm{pH}$ 6.81) with a carbon dioxide level of $17 \mathrm{mmHg}(38-50 \mathrm{mmHg})$ and a bicarbonate level of $3 \mathrm{mmol} / \mathrm{L}(22-26 \mathrm{mmol} / \mathrm{L})$, lactate of $4.8 \mathrm{mmol} / \mathrm{L}(0.5-2.2$ $\mathrm{mmol} / \mathrm{L})$, leukocyte count of $10 \times 10^{9} / \mathrm{L}\left(4-11 \times 10^{9} / \mathrm{L}\right)$, sodium of $147 \mathrm{mmol} / \mathrm{L}(135-145 \mathrm{mmol} / \mathrm{L})$ and a creatinine of 1188 $\mathrm{mmol} / \mathrm{L}(64-111 \mathrm{mmol} / \mathrm{L})$. Blood cultures drawn on arrival later revealed gram-negative bacteremia. When a urinary catheter was introduced, $1.2 \mathrm{~L}$ of purulent and bloody urine was evacuated. $\mathrm{He}$ was diagnosed with urosepsis, started on antimicrobial therapy (vancomycin and ceftriaxone), a bicarbonate infusion, fluid resuscitated, and subsequently transferred to the Intensive Care Unit (ICU) at a tertiary care centre.

Upon arrival to the ICU, the patient's temperature was $32^{\circ} \mathrm{C}$, heart rate $58 \mathrm{bpm}$, and a blood pressure of 151/54 $\mathrm{mmHg}$. On examination, both pupils were sluggish, he had hypoactive bowel sounds and absent peripheral reflexes; he only retracted to painful stimuli. A computed tomography (CT) scan of the head did not show any acute abnormality. Repeat blood work showed a hemoglobin of $65 \mathrm{~g} / \mathrm{L}(130-180 \mathrm{~g} / \mathrm{L})$, leukocyte count of $7.4 \times 10^{9} / \mathrm{L}$, creatinine of $1337 \mathrm{mmol} / \mathrm{L}$, urea of 55.1 $\mathrm{mmol} / \mathrm{L}(3.0-9.2 \mathrm{mmol} / \mathrm{L})$, sodium of $143 \mathrm{mmol} / \mathrm{L}$ and a negative toxicology screen. His urinary catheter continued to drain gross hematuria. Point-of-care ultrasound showed signs suggestive of hydronephrosis and a subsequent CT confirmed distention of both ureters and renal collecting systems without any source of obstruction. The antibiotic regimen was broadened to piperacillin-tazobactam; passive rewarming and continuous renal replacement therapy (CRRT) were subsequently started.

A thyroid panel completed in the ICU showed a serum thyroid stimulating hormone of $146.92 \mathrm{mIU} / \mathrm{L}(0.35-4.90$ $\mathrm{mIU} / \mathrm{L})$, free thyroxine $\left(\mathrm{T}_{4}\right)<5.2 \mathrm{pmol} / \mathrm{L}(9-19 \mathrm{pmol} / \mathrm{L})$ and a free triiodothyronine $\left(\mathrm{T}_{3}\right) 1.57 \mathrm{pmol} / \mathrm{L}(2.76-6.45 \mathrm{pmol} / \mathrm{L})$. The patient was concurrently diagnosed with myxedema coma, started on stress doses of hydrocortisone $100 \mathrm{mg}$ every 8 hours and given intravenous levothyroxine $200 \mathrm{mcg}$ once, followed by $50 \mathrm{mcg}$ daily based on his weight. The patient slowly regained neurological function and was liberated from mechanical ventilation 4 days after admission. Once neurological function improved, the corticosteroids were withdrawn after confirmation of a normal cortisol level $(552 \mathrm{nmol} / \mathrm{L})$. A detailed search into his past medical history revealed a remote ultrasound finding indicating the presence of a thyroid nodule. After recovery from his critical illness, the patient disclosed that he had previously received a diagnosis of hypothyroidism, but he had declined to see his physician for any further follow up.

The patient's blood and urine cultures speciated to Proteus mirabilis; antibiotics were stepped down to ceftriaxone to complete a 10-day course. Repeat ultrasound on day 5 showed persistent hydroureteronephrosis requiring insertion of bilateral nephrostomy tubes. CRRT was discontinued, he was switched to oral levothyroxine and was deemed stable for transfer to the medical ward.

\section{Discussion}

Myxedema coma is a state of severe and often life-threatening hypothyroidism. ${ }^{1,2}$ Mortality is reported ranging from $25-60 \%{ }^{1}$ and retrospective studies in Japan ${ }^{3}$ and India ${ }^{4}$ have shown inhospital mortality of $29.5 \%$ and $66.6 \%$ respectively. In addition, mortality tends to be higher in those patients who are non-adherent with previously prescribed thyroid replacement medication. ${ }^{5}$ In Canada, while there are no epidemiological studies outlining the incidence of myxedema coma, there were 83 reported deaths from this condition from 2000 to $2015 .{ }^{6}$ However, this does not capture the true incidence of this condition in Canada, as patients who were treated successfully would not be included in these reports. The diagnosis is more common in women and has a number of triggers including cold temperatures, stroke, heart failure, sedatives, antipsychotics, anesthetics, non-adherence with thyroxine replacement, infection and sepsis. ${ }^{1,2,4}$ The latter 3 are the most common major precipitating factors and often lead to higher mortality., ${ }^{2,4,7}$ As presented in this case report, untreated hypothyroidism coupled with the obstructive uropathy and bacteremia triggered the progression to myxedema coma.

Signs and symptoms of myxedema coma include decreased mental status, coma, hypothermia, respiratory depression, bradycardia, hypotension, hyponatremia, general cachexia, delayed tendon reflexes, and non-pitting edema. ${ }^{1,2}$ This constellation of symptoms results from low serum $\mathrm{T}_{3}$ levels (Figure 1).

Low thyroid hormone levels directly cause suppression of cardiac activity, leading to bradycardia and peripheral vasoconstriction which may lead to cardiogenic shock. It also leads to a decrease in basal metabolic rate which impairs thermogenesis and the behavioural responses for heat production. ${ }^{8}$ Decreased central nervous system activity causes depressed level of consciousness; altered vascular permeability leads to edema; reduced glomerular filtration rate and free water retention may lead to hyponatremia. If severe enough, hyponatremia may result in seizures. Finally, decreased gluconeogenesis in the hypometabolic state can lead to hypoglycemia, further exacerbated by precipitating factors 


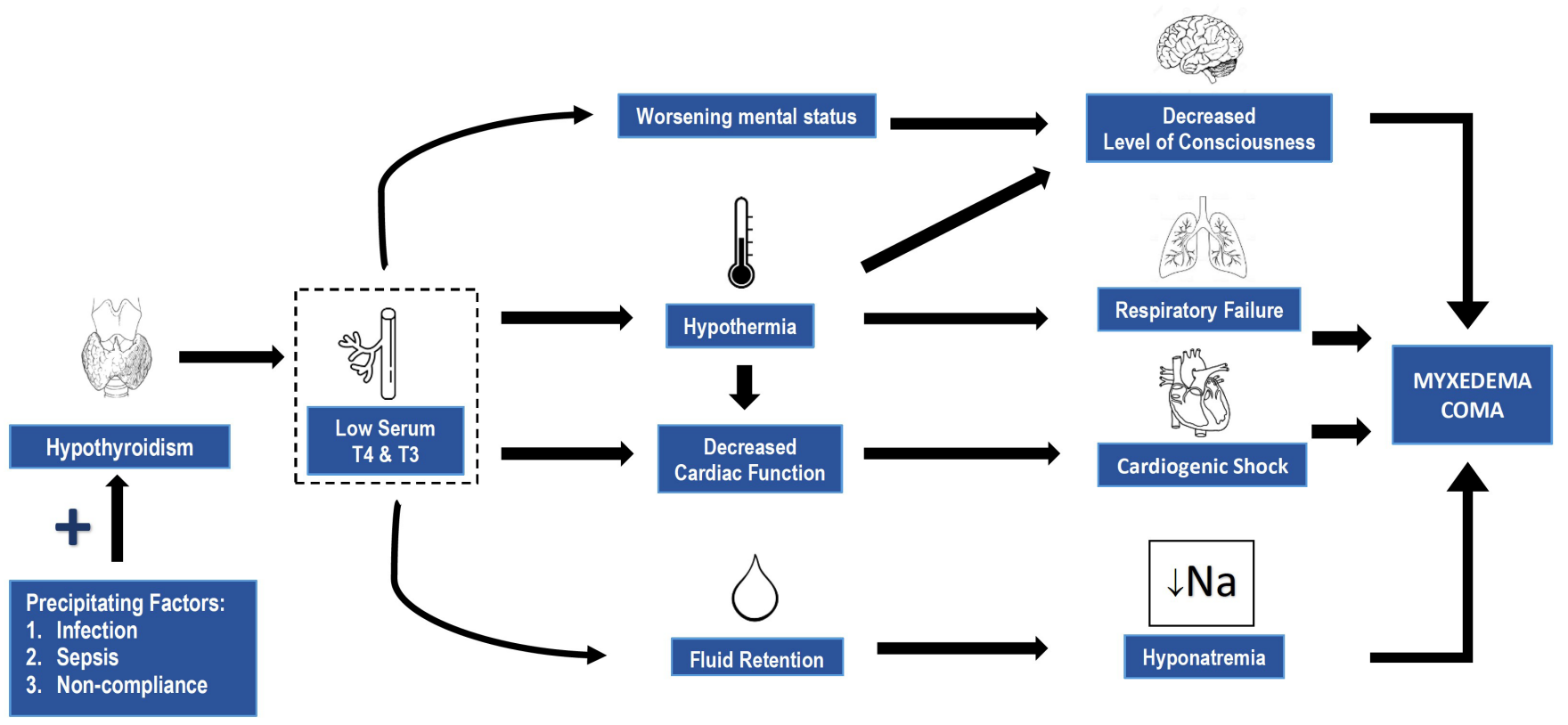

Figure 1. Pathogenesis of myxedema coma. Adapted from Matthew et al. ${ }^{9}$

including sepsis or adrenal insufficiency., ${ }^{2,9}$ The patient presented in this report did not experience hyponatremia, hypoglycemia, edema or hypotension which clouded the overall picture. The only signs initially present were decreased level of consciousness and profound hypothermia, which, without knowledge of his previously diagnosed hypothyroidism, were attributed solely to his diagnosis of urosepsis. By the time he arrived to the ICU his presentation progressed to include bradycardia, respiratory depression and absent reflexes. In a similar setting of multiple pathological processes (renal failure, urinary retention, bacteremia and sepsis) concomitant diagnoses may obscure investigation and diagnosis of underlying myxedema coma.

While the diagnosis of myxedema coma could be confirmed with serological thyroid markers, the literature recommends that treatment should not be delayed and be given based on clinical presentation alone. ${ }^{1,2,7}$ Myxedema coma is not a common presentation, so clinicians must have a high degree of suspicion in order to avoid misdiagnosis. ${ }^{10}$ The diverse constellation of possible presentations, combined with a vague and often non-specific history or physical examination, often make the diagnosis of myxedema coma elusive. ${ }^{10}$ As presented here, the initial presentation of myxedema coma may drive the clinician to focus on and treat the precipitating factor alone rather than addressing the underlying hypothyroidism that also exists. For these reasons, the differential diagnosis of any patient with severe hypothermia should include myxedema coma as a potential cause (Table 1), that while uncommon, carries a high mortality rate if not identified promptly. ${ }^{1-4}$

Urosepsis and septic shock are common triggers that may have presenting features similar to myxedema coma (hypothermia, hypotension, electrolyte disturbances) creating a diagnostic dilemma. As such, it is important to keep a wide differential to prevent delays in recognition and treatment of concurrent thyroid hormone derangement. ${ }^{4,5,9}$

Management of myxedema coma should take place in an ICU. The respiratory acidosis and respiratory failure often seen in deep coma is a common cause of mortality; as such, mechanical ventilation may be needed. ${ }^{1,2,4}$ Stress dose corticosteroids, intravenous thyroid replacement therapy, and supportive care with emphasis in management of the precipitating factors ${ }^{1,10}$ constitute the basis of treatment. There is no clear consensus on whether both levothyroxine $\left(\mathrm{T}_{4}\right)$ and liothyronine $\left(\mathrm{T}_{3}\right)$ should be used simultaneously. ${ }^{3}$ The need for a rapid increase in thyroid hormone levels should be balanced against the risk of precipitating cardiac events such as arrhythmias or acute coronary syndrome ${ }^{2}$ associated with their administration. As such, intravenous levothyroxine is given at a loading dose of 200-400 mcg with subsequent daily doses of $1.2 \mathrm{mcg} / \mathrm{kg} /$ day. ${ }^{11}$ This approach has a slow and predictable onset of action with fewer reported adverse effects. ${ }^{1,2}$ Co-administration of liothyronine may be beneficial in cases where the peripheral $\mathrm{T}_{4}$ to $\mathrm{T}_{3}$ conversion may be impaired, as is often the case in severe illness. ${ }^{1,2}$ Liothyronine has a quicker onset of action than levothyroxine and has better blood-brain barrier penetration; however, its unpredictable serum levels may increase cardiac related mortality. ${ }^{2}$ Whenever used, it is given at a loading dose of 5-20 mcg with subsequent maintenance dose of $2.5-10 \mathrm{mcg}$ every 8 hours. In this patient, intravenous levothyroxine was used as the main method of thyroid hormone replacement, which was sufficient in steadily improving his clinical status over the course 
Table 1. Differential Diagnosis of Hypothermia

\begin{tabular}{|c|c|}
\hline $\begin{array}{c}\text { Increased Heat } \\
\text { Loss }\end{array}$ & $\begin{array}{l}\text { - Environmental exposure } \\
\text { - Induced vasodilation (Drugs, Alcohol, } \\
\text { Toxins) }\end{array}$ \\
\hline $\begin{array}{l}\text { Decreased Heat } \\
\text { Production }\end{array}$ & $\begin{array}{l}\text { - Endocrinologic disease (Hypopituitarism } \\
\text { - Adrenal insufficiency Hypothyroidism) } \\
\text { - Impoglycemia } \\
\text { - Impaired shivering }\end{array}$ \\
\hline $\begin{array}{l}\text { Impaired } \\
\text { Regulation }\end{array}$ & $\begin{array}{l}\text { - Spinal cord transection } \\
\text { - Cerebrovascular accident } \\
\text { - Subarachnoid hemorrhage } \\
\text { - Hypothalamic dysfunction } \\
\text { - Drugs: anxiolytics, antidepressants, } \\
\text { antipsychotics, opioids, anti- } \\
\text { hyperglycemics, beta blockers }\end{array}$ \\
\hline Other & $\begin{array}{l}\text { - Sepsis } \\
\text { - Pancreatitis } \\
\text { - Carcinomatosis } \\
\text { - Uremia } \\
\text { - Vascular insufficiency }\end{array}$ \\
\hline
\end{tabular}

of 4 days. Follow up measurement of thyroid hormone levels are recommended every 2-3 days ${ }^{1,11}$ to allow for assessment of response to therapy and make dose adjustments as necessary.

Supportive management in myxedema coma also includes corticosteroids and passive rewarming. Hypotension can be both the result of low thyroid hormone levels or concomitant adrenal insufficiency. Stress doses of corticosteroids should be empirically given prior to administering levothyroxine and withdrawn soon after hemodynamic stability is achieved and there is no suspicion of ongoing cortisol deficiency. Hydrocortisone 100 $\mathrm{mg}$ intravenously every 8 hours is often used ${ }^{2}$. Passive warming is an effective way of increasing body temperature without compromising hemodynamics. Blankets and heating pads are effective ways of slowly rewarming a patient while avoiding the peripheral vasodilation that may exacerbate hypotension and distributive shock. ${ }^{2}$ Finally, appropriate management of the precipitating factors requires urgent attention. Broad spectrum antibiotics, fluid resuscitation, and hemodialysis or renal replacement therapy as necessary will help avoid multi-organ dysfunction and improve survival. ${ }^{9}$

\section{References}

1. Leung AM. Thyroid emergencies. J Infus Nurs 2016;39(5):281-6.

2. Pangtey GS, Baruah U, Baruah MP, et al. Thyroid emergencies: New insight into old problems. JAPI 2017;65(8):68-76.

3. Ono $\mathrm{Y}$, Ono $\mathrm{S}$, Yasunaga $\mathrm{H}$, et al. Clinical characteristics and outcomes of myxedema coma: Analysis of a national inpatient database in Japan. J Epidemiol 2017;27:117-22.

4. Murthy TA, Rangappa P, Jacob IPR, et al. Myxoedema coma in adults: Experience from a tertiary referral hospital intensive care unit. Indian J Anesth 2015;59(5):315-7.

5. Dutta P, Bhansali A, Masoodi SR, et al. Predictors of outcome in myxedema coma: a study from a tertiary care centre. Crit Care 2008;12:R1.

6. Statistics Canada. Table 102-0524. Deaths, by cause, Chapter IV: Endocrine, nutritional and metabolic diseases (E00 to E90), age group and sex, Canada. Available at: http://www5.statcan.gc.ca/cansim/ a26?lang=eng\&retrLang=eng\&id $=1020524 \&$ pattern $=\& c s i d=$.

7. Gupta KJ. Myxedema coma: a sleeping giant in clinical practice. Am J Med 2013;126(12):e3-e4

8. Danzl DF. Hypothermia and Frostbite. In: Kasper DL, Fauci AS, Hauser SL et al, eds. Harrison's principles of internal medicine, $19^{\text {th }}$ edition. New York: McGraw-Hill; 2015.

9. Mathew V, Misgar A, Ghosh S, et al. Myxedema coma: a new look into an old crisis. J Thyroid Res 2011;1-7.

10. Dubbs SB, Spangler R. Hypothyroidism causes, killers, and life-saving treatments. Emerg Med Clin North Am 2014;32(2):303-17.

11. Jonklaas J, Bianco AC, Bauer AJ, et al. Guidelines for the treatment of hypothyroidism. Thyroid 2014;(12):1670-751. 